\title{
KNOWLEDGE AND ADOPTION TOWARDS GOOD AGRICULTURAL PRACTICES: A SPECIAL REFERENCE TO LEAFY VEGETABLE CULTIVATION IN KALUTARA DISTRICT
}

\author{
Abayarathna YSU and Sandika AL* \\ Department of Agricultural Economics and Extension, Faculty of Agriculture, \\ University of Ruhuna, Mapalana, Kamburupitiya
}

\begin{abstract}
This study attempted to investigate the farmers' knowledge and adoption towards Good Agricultural Practices (GAPs) for leafy vegetable cultivation. Bandaragama Divisional Secretariat of Kalutara District was selected as the study area by considering the significant number of target population scattered in the area. A hundred respondents were selected randomly out of 320 leafy vegetable growers in the study area. Data were collected by employing an interview schedule with systematic observation. Farmers were aware of GAPs. Nevertheless, their adoption level was low to moderate level due to practical issues of the implementation of GAPs. There was a positive correlation of knowledge and adoption $(r=0.862, p=0.01)$ indicating that a high level of adoption to the GAPs by the knowledgeable farmers. Therefore, appropriate training and knowledge programmes need to be implemented to increase the adoption level. Further, the low level of adoption of GAPs was observed and the reasons might be farmers' negative attitudes toward the implementation of GAPs, negligence and low investment ability to practice GAPs activities. Therefore, relevant private and public institutes have to pay great attention in this regard. And also, it can be suggested that the public and private sectors' helping hand is required to transform farmers as agripreneurs to run an agribusiness enterprise with maintaining high-quality standards through effective and efficient supply chain management.
\end{abstract}

Keywords: Adoption, Adoption index, Good Agriculture Practices, Knowledge and Knowledge index

\section{INTRODUCTION}

Significant numbers of empirical evidence have proved that farmers tend to apply higher dosages of inorganic fertilizers and agrochemicals to increase production without considering the actual requirement as well as human and environmental health. On the other hand, farmers do not follow safety measures in the use of agrochemicals. Therefore, World Health Organization (WHO) has introduced a five 'Golden Rules' (GR) viz., always read and understand the label information, handling chemicals carefully, maintain sprayers, practice good personal hygiene and always use appropriate protective cloths when buying, transporting, storage, application and disposing of chemical wastes of agrochemical. The safety

\footnotetext{
*Corresponding author: sandika@agecon.ruh.ac.lk
}

measures need to be adopted while using agrochemicals because of its' hazardous nature (WHO 1990). Therefore, the various institutions viz., government and NGOs have attempted to increase farmers' knowledge on safety uses of agrochemicals through various approaches such as Farmers Field Schools (FFS) (Sandika 2011).

Moreover, many attempts have been made in recent years in Sri Lanka to study the pesticide use practices in vegetable cultivation, especially in the upcountry and mid-country to provide the status of the issue and to develop guidelines to minimize pesticide use (Chandrasekara et al. 1985; Selvaraj and Thiruchelvam 2007; Sumith 2009; Marasinghe et al. 2011; Chaminda 2012; Sumith and 
Munkittrick 2011, Padmajani et al. 2014; Pathirana et al. 2015; Marasinghe et al. 2017). On this background, Nishantha et al. (2016) pointed out the need for paradigm shifts in insect pest and disease management in crop production because it is a highly debatable and sensitive issue in the present scenario. Many stockholders such as farmers, consumers, researchers, input suppliers and policymakers at present are debating on how to balance issues of the farmers, human health and environment. In traditional forms of vegetable cultivation, adaptation to pests had been achieved by naturally selected resistant varieties and traditional cultivation practices. However, the need for increased vegetable production has led to the adoption of more intensive cultivation practices which increases insect pest and disease attacks and a greater reliance on pesticides as the major form of control. While breakthroughs in novel methods of control are possible, their immediate impact might uncertain and certainly unproven. Hence, at present, there is far more potential to improve pest management by fully utilizing the control methods and practices currently available (Norton 1996). What is required is a better understanding of farmers' problems that will enable key constraints to be reduced and more appropriate control strategies to be designed (Bentley and Andrews 1996; Moore 1997). Farmers' needs for higher and profitable production of 'safer foods' to consumers and guidelines to curtail exposure levels of toxic chemicals are summarized below based on the farmers' suggestions and findings of the present study. In this context, the FAO has introduced the "Good Agriculture Practices" (GAPs) a framework to balance the issue with wide-ranging objectives. The framework identifies seven generic components of GAPs, including soil and water management, crop production and protection, post-harvest and onfarm processing and storage, human welfare, health and safety (FAO 2003). There is a growing demand for sustainable agricultural development in response to the environmental impacts of conventional agriculture (Baudoin et al. 2013).
It was empirically identified that leafy vegetable growing farmers are applying overdosage of agrochemicals for their cultivation like other vegetable farmers Nishantha et al. (2016). The negative impacts of applying overdosage of agrochemical are affecting to consumer health, environment and farmers' profit (Nishantha et al. 2016). Leafy vegetables can absorb heavy metals through unclean soil and irrigation water (Kananke et al. 2014). Further, it can absorb the metals deposited on plant surfaces when plants are exposed to polluted environments. $\mathrm{As}, \mathrm{Pb}, \mathrm{Hg}$ and $\mathrm{Cd}$ are commonly reported non -essential toxic heavy elements, that are associated with many chronic diseases in human beings (Kananke et al. 2014). To safeguard producers, consumers and the environment from this hazardous condition, GAPs would be an effective option in agricultural fields. In such a context, the Department of Agriculture, Sri Lanka has suggested the GAP programme to establish GAPs among farmers (Department of Agriculture 2018). Its key objective is to increased good practices and minimizing chemical uses. This programme has been implemented in Gampaha, Kalutara and few other Districts in Sri Lanka. Yet, the effectiveness of the programme, regarding the extent of farmers' knowledge and adoption on GAPs of leafy vegetables is still not revealed.

In respect to the leafy vegetable cultivation, there are five types of leafy vegetables namely Kan Kun (Ipomosea aquatica), Mukunuwenna (Alternantheras essilis), Nivithi (Basella alba), Gotukola (Lasia spinosa), Thampala (Amaranthus viridis) and Sarana (Trianthem aportulacastrum) are popular among Sri Lankans. Leafy vegetables are produced in several areas in Sri Lanka. Wellampitiya, Kolonnawa, Kottawa, Piliyandala, Bandaragama and Kahathuduwaarea of Colombo and Kaluthara districts are the dominant places for leafy vegetable cultivation in Sri Lanka ( Kananke et al. 2014).

On this background, this study attempted to investigate the farmers' knowledge and adop- 
tion towards GAPs for leafy vegetable cultivation with the specific objectives of the identification of farmers' level of knowledge and adoption on GAPs for leafy vegetable cultivation, and the relationship of knowledge and adoption to GAPs implementation for leafy vegetable cultivation and to make appropriate suggestions to increase farmers' knowledge and adoption on GAPs for leafy vegetable cultivation.

\section{MATERIALS AND METHODS}

Bandaragama DS of Kalutara District was selected as the study area for the research by considering the significant number of the target population. There were 320 leafy vegetable growers in the study area. The respondents were scattered over the selected area. Therefore, the survey methodology was employed for the study. A hundred respondents were selected for a questionnaire survey by using a simple random sampling method with the help of a sampling frame (farmers list) which was prepared with the assistance of the district office of the Department of Agriculture.

The data were collected with the help of an interview schedule and with systematic observation. A draft interview schedule was initially structured based upon objectives and information requirements for this study. Then, this draft interview schedule was pre-tested and modified accordingly.

The method followed by Sandika et al. (2014) and Pandit et al. (2017) was adopted to measure the response on farmers' knowledge and adoption towards GAPs. The Likert scale was used in subjective form based upon the important dimension of GAPs like soil management, water management, crop production, crop protection, harvest, post-harvest and human health and hygiene. A scale with five levels $(5=$ very high, $4=$ high, $3=$ neutral, 2 =weak, 1 = very weak) for knowledge on different GAPs practices and 3 levels scale $(2=$ always $1=$ sometime $0=$ never) was used to determine the adoption level. Also, important demographic variables such as gender, age, farming and other alternative occupation, income, education, sources of information (interpersonal and mass media) were collected to recognize the factors affecting knowledge and adoption. Data analysis was done by applying the following equation.

The knowledge and adoption levels of GAPs were calculated by applying the knowledge index and adoption index, respectively. Knowledge index and adoption index were measured using the formula developed by Rogers and Shoemake (1971).

Knowledge index $=($ Known practices $/$ Total practices of GAP) x $100 \ldots$ (i)

Adoption index $=($ Adopted practices $/$ Total adoptable practices of GAP) x 100

Index values' range was 1 to 100 . The categorization was finally done as poorly (1 to 35 ), moderate (36 to 70 ) and highly (71 to 100 ) knowledgeable or adopted based upon the index marks. Further, the knowledge and adoption gap was calculated by using a 100 minus index value. The Pearson product movement correlation test was performed to ascertain the relationship between the different variables.

\section{RESULT AND DISCUSSION \\ Demographic information of respondents}

The majority of respondents (54\%) were females whereas $82 \%$ of respondents were married. About $48 \%$ of farmers belonged to the 31 -50 age group whereas $40 \%$ of farmers were above 50 years. The rest of them were in the 21-30 years age category (12\%). The results proved that young farmers' involvement in agriculture was low as observed by many authors Sandika (2011). Out of all the respondents, $44 \%$ of respondents have studied up to GCE ordinary level (OL) while $30 \%$ of farm- 
ers have studied up to GCE advance level (AL) and the rest of them have primary (14\%) or graduate $(12 \%)$ level education. It revealed that the majority of farmers have educated up to GCE OL or AL. Therefore, there is a high potential to popularize the GAPs among the respondents. An attempt was made to recognize the main occupation of the respondents. About $46 \%$ of respondents' main occupation was leafy vegetable cultivation while others were employed in private or government sector jobs, business, or other self-employment activities. The majority of respondents (75\%) have less than 10 years of experience in the field of agriculture which is essential for successful leafy vegetable cultivation. Further average year of experience in leafy vegetable farming was 8 years.

Out of the different types of leafy vegetables, Mukunuwenna (Alternantheras essilis) 62\%, Sarana (Trianthem aportulacastrum) 56\%, Kan Kun (Ipomosea aquatica) 51\%, Thampala (Amaranthus viridis) 45\%, Gotukola (Lasia spinosa) 38\% and Nivithi (Basella alba) $35 \%$ were the popular varieties among the respondents.

The land is a very limited factor and the opportunity cost of land is also very high in Sri Lanka. Therefore, there is a limited number of large-scale cultivations. On this background, small scale cultivations need to be promoted among the interested farm groups. When considering the cultivated land extent, it was varied from 0.02 to 0.5 acres with an average of 0.06 acres. Further yield, is one of the most important factors. Respondents' yield varied from 30 to 350 bundles (Weight per bundle = $200 \mathrm{~g}$ ) per day with an average of 127 bundles. However, $42 \%$ of respondents produced 50 to 150 bundles per day. About 27\% produced 150 to 250 bundles per day whereas $15 \%$ and $16 \%$ produced less than 50 and more than 250 bundles per day, respectively. Moreover, half of the respondents said that they are practicing daily harvesting whereas $30 \%$ of respondents practicing twice per week and the rest of them harvesting once per week.

The range of the cost of production was reported from LKR 29,650 to 179,100 per hectare per month with an average of LKR 84,990 per hectare per month which depends on the type of crop. Monthly income was varied from LKR 24,710 to 1,853,250 per hectare with an average income of LKR 773,920 per hectare per month (Table 1). The leafy vegetable cultivation is a labour intensive venture. An attempt was made therefore to identify the source of labour since labour scarcity is very high in this area. All of the respondents used family labour as the main labour source while $70 \%$ stated that they use the hired labour also when required more labour from daily payment basis.

\section{Knowledge and adoption of the practices}

The main objective of this study was to investigate the farmers' knowledge and adoption of GAPs for leafy vegetable cultivation. It was measured by considering the main dimension of soil management, water management, crop production, crop protection, harvest, postharvest and human health and hygiene (Fig. 1). Respondents' knowledge on water man-

Table 1: Cost of production and income of the respondents

\begin{tabular}{llll}
\hline $\begin{array}{l}\text { Cost of production } \\
\text { (LKR per hectare per month) }\end{array}$ & $\begin{array}{l}\text { Income } \\
\text { (LKRs per hectare per month) }\end{array}$ \\
\hline Category & Percentage & Category & Percentage \\
Less than 37,100 & 22 & Less than 247,100 & 01 \\
$37,100-74,150$ & 41 & $247,101-741,300$ & 26 \\
$74,150-123,550$ & 19 & $741,301-1,235,500$ & 24 \\
More than 123,551 & 18 & More than $1,235,501$ & 49 \\
\hline
\end{tabular}


Table 2: Farmers' knowledge and adoption of GAPs

\begin{tabular}{lll}
\hline & \multicolumn{2}{l}{ Number of farmers (\%) } \\
\cline { 2 - 3 } Categories & Knowledge level & Adoption level \\
\hline Poorly (1 to 35) & $02(02 \%)$ & $33(33 \%)$ \\
Moderate Moderate (36 to 70) & $62(62 \%)$ & $62(62 \%)$ \\
Highly (71 to 100). & $36(36 \%)$ & $05(05 \%)$ \\
\hline
\end{tabular}

agement, harvest, post-harvest and human health and hygiene was good as compared to other dimensions. Further, as compared to knowledge level the farmers' adoption level was low for all dimensions of GAPs as shown in Figure 1. The overall categorization was done as poorly ( 1 to 35 ), moderate (36 to 70 ) and highly (71 to 100) by considering the above seven dimensions together based upon the overall index marks. Results are depicted in Table 2. According to the findings, farmers' adoption of GAPs was low even though they were knowledgeable about the concept (Fig.1).

Farmers' negative attitude to implement GAPs and negligence to maintain the quality and low investment ability were identified as the reasons for these results. Therefore, this matter should be taken into consideration by relevant authorities. The results of the study done by Sandika et al. (2014) related to the confectionery producers showed that producers' adoption level to Good Manufacturing Practices (GMP) was very low due to some reason such as lack of knowledge and produces poor attitudes to implement the GMP, negligence and financial issues. It is, therefore, as pointed by Roger and Shoemaker (1971) followed by Pandit et al. (2017) suitable methods need to be implemented by the relevant authorities to increase the adoption level in this regard.

It can be observed that the adoption gap is almost $50 \%$ for all the aspects of GAPs (Fig.2). This result was in parallel with the result of Pandit et al. (2017). They have done a study on 'Adoption of good agricultural practices (GAPs) in Basmati (Scented) rice cultivation in Karnal and Kurukshetra dis- tricts of Haryana state. Their results showed that the awareness and the adoption of the critical GAPs in the basmati production system were at the lowest level, whereas the benefits of adoption were well understood by the farmers. The awareness level of farmers about GAPs in basmati rice was found to be $58.33 \%$, whereas adoption was only $27.41 \%$ which is even less than half of the awareness level.

High adoption gap was reported to crop protection, human health and hygiene aspects. This result is clearly in line with the previous empirical evidence by Nishantha et al. (2016). Moreover, the majority of farmers knew agrochemicals are harmful to the environment and the health. But they were unaware of the unacceptable levels of toxic chemicals present in their products. Farmers, therefore, demand a system to upgrade their knowledge on this issue. Further, the non-availability of acceptable, efficient, alternate non-pesticide-based pest and disease control methods (i.e. botanicals, pheromones, bio-control agents, companion crops, flowering weeds, eco-system management methods) hinder minimizing pesticide use in leafy vegetable cultivation. Therefore it is important to introduce a community-level surveillance system via mobile or ICT tools to make farmers aware of pests and disease incidences and human health and hygiene aspects. Further, it is worth implementing policies for regular monitoring of pesticide residues in vegetables. This should be therefore taken into consideration by the relevant authorities.

\section{Factors affecting knowledge and adoption}

The adoption level was found significantly and positively correlated with knowledge lev- 
$\mathrm{el}(\mathrm{r}=.862, \mathrm{p}=0.01)$ indicating that farmers' adoption level can be increased by increasing their knowledge on GAPs for leafy vegetable cultivation. Further, farmers' experience was negatively significant with knowledge on GAPs $(\mathrm{r}=-0.32, \mathrm{p}=0.01)$ whereas extension service $(\mathrm{r}=0.23, \mathrm{p}=0.05)$ and mass media $(\mathrm{r}$ $=0.25, \mathrm{p}=0.01) \quad$ were positively correlated with knowledge on GAPs. Other demographic variables were not correlated with the knowledge index. Moreover, there were no socio-economic variables correlated with the adoption of GAPs. These results were in line with the result of Pandit et al. (2017). They have considered about five independent variables with the adoption of GAPs showed that age was found to be non-significantly correlated whereas education and mass media exposure was found to be highly correlated with adoption of GAP criteria. Social participation and landholding were positively correlated with the adoption of the GAPs criterion. Base on the empirical evidence of this study farmers' adoption of GAPs for leafy vegetable cultivation can be increased by educating them on GAPs through effective extension activities and mass media.

Farmers' suggestions to popularize GAPs among leafy vegetable cultivators were also

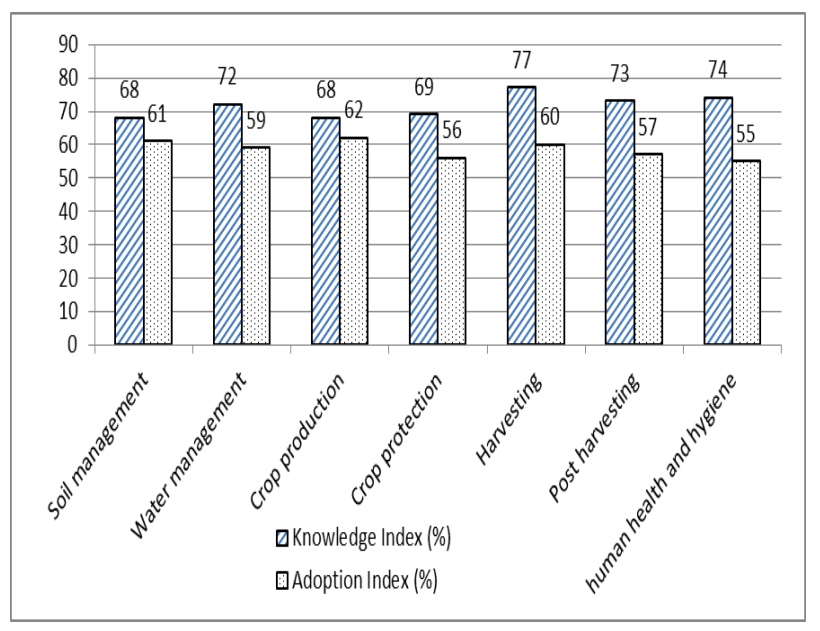

Figure 1: Farmers' Knowledge and adoption towards GAPs for leafy vegetable cultivation collected. Improving knowledge on GAPs through appropriate extension teaching methods such as training programmes, advice from agriculture instructors and other agriculture officers, providing more loans, insurance, additional markets and other infrastructure facilities to implement GAP activities were the suggestions given by the respondents. These suggestions are still aligned with the required supporting services explain by Mosher (1978) for agricultural development. Further, as the Department of Agriculture pointed out in its training manual, farmers need to be empowered as agribusiness entrepreneurs to improve livelihood as a professional venture.

\section{CONCLUSION}

Respondets' knowledge about Good Agricultural Practices (GAP) were rated as moderate to high level. But, their adoption level towards GAPs were reported as low to moderate level. Therefore, appropriate training and knowledge programs need to be introduced to increase the adoption level through enhancing the knowledge on GAPs because both variables were high and positively correlated.

The farmers' negative attitude toward the implementation of GAPs, negligence, and low investment ability toward GAPs, etc. are

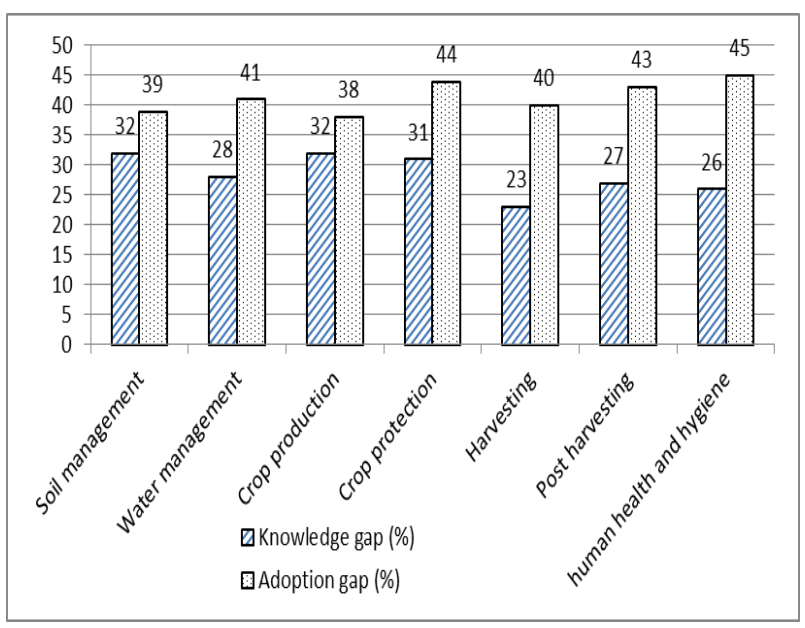

Figure 2: Farmers' Knowledge and adoption gap towards GAPs for leafy vegetable cultivation 
some causes of the low level of adoption to GAPs.Therefore, relevant private and public institutes need to pay more attention in this regard. Also, they should give their helping hand to improve farmers' entrepreneurship to run agribusiness enterprises. It will develop an efficient and effective supply chain and will increase the quality of the final product.

Also, the authors are suggesting future research through collecting data from other areas of Sri Lanka with larger samples to have a more comprehensive study related to leafy vegetable cultivation and application of GAPs.

\section{ACKNOWLEDGMENT}

We are grateful to the vegetable farmers who participated in the survey and for patiently listening to our long list of questions with direct answers.

\section{REFERENCES}

Baudoin W, NonoWomdim R, Lutaladio N, Hodder A. Castilla N, Leonardi C, De Pascale S, Qaryouti M and Duffy R 2013 Good agricultural practices for greenhouse vegetable crops, Principles for Mediterranean climate area, United Nation Food and Agriculture Organization, Rome, http:// www.fao.org/3/a-i6787e.pdf.

Bentley J and K Andrews 1996 Through the Roadblocks: IPM and Central American Smallholders. International Institute for Environment and Development, 400p.

Chandrasekara AI, Wettasinghe A and Amarasiri S 1985 Pesticide usage by vegetable farmers. Annual Research Conference, ISTI, Gannoruwa, Sri Lanka, $79-87 \mathrm{p}$.

Chaminda KGS 2012 Environmental impact and use of agrochemicals in cattle feed and its effect on milk, Nuwara Eliya Sri Lanka. Proceedings of the $1^{\text {st }}$ National Symposium on Potential Health and Environmental Impacts of
Exposure to Hazardous Natural and Manmade Chemicals and their Proper Management, University of Peradeniya, 27-30p.

Department of Agriculture, 2018. Agricultural Entrepreneurship Development Training Programme, Department of Agriculture, Peradeniya.

Food and Agriculture Organization 2003 Good agricultural practices, United Nations Food and Agriculture Organization, Rome, http://www.fao.org/old/ foro/bpa/pdf/good.pdf.

Kananke T, Wansapala $\mathrm{J}$ and Gunaratne A 2014 Heavy metal contamination in green leafy vegetables collected from selected market sites of Piliyandala area, Colombo District, Sri Lanka, American Journal of Food Science and Technology, 2 (5):139 - 144.

Marasinghe JP, Magamage C, Shiromi MGD and AGP Aravinda 2011 Organophosphate pesticide residues in food commodities in Sri Lanka; A Review. Annals of the Sri Lanka Department of Agriculture, 113: 81-93.

Marasinghe JP, Hemachandra KS, Nugaliyadde L and Karunaratne SHPP 2017 Control failure of Sri Lankan whitefly (Bemisia tabaci) is due to high resistance development against recommended insecticides. Journal of National Science Foundation Sri Lanka, 45 (1): 25-33.

Moore N 1997 Information Society. In: World InformationUNESCO Publication, Paris. 271-284pp.

Mosher AT 1978 An Introduction to Agricultural Extension, Agriculture Development Council, New York, USA.

Nishantha KMDWP, Sandika AL, Babu AGC, Hettiarachchi HASN, Pushpanjali K, Abeytilakeratna PD, Nugaliyadde MM 2016 Farmers' knowledge and attitudes on pesticide usage in vegetable cultivation in Sri Lanka, Journal of Tropical Agricultural Research and Extension, 19 (3):249 
$-252$.

Norton G, 1996 Corporative strategies for pest management: Making it happens. In: Pest management strategies in Asian monsoon agro-ecosystems. Kyushu National Agriculture Experimental Station, Japan. 21-31pp.

Padmajani MT, Aheeyar MMM and Bandara MACS 2014 Assessment of Pesticide Usage in Upcountry Vegetable Farming in Sri Lanka, HARTI Research Report No: 164. Hector Kobbekaduwa Agrarian Research and Training Institute, Colombo, Sri Lanka.

Pandit $M$, Nain S, Singh R, Kumar S and Chahal VP 2017 Adoption of Good Agricultural Practices (GAPs) in Basmati (Scented) rice: A study of prospects and retrospect. Indian Journal of Agricultural Sciences, 87 (1):3641.

Pathirana KPSR, Katukurunda KGSG, Dilhani RADI, Marapana RAUJ, Jayasinghe JMJK and Navaratne SB, 2015 Pesticide contaminated crop residues and water usage for dairy cattle rearing in Walapane DS division, Sri Lanka. International Journal of Innovative Research in Technology.2 (6):216-220.

Rogers EM and Shoemaker FF 1971 Communication of Innovation, Collier Macnillan publishers, New York, USA.

Sandika AL 2011 Knowledge and adoption toward 'Golden Rules' in agrochemicals usage: A case of paddy farmers at Buttala area, Proceedings of $67^{\text {th }}$
Annual session of the Sri Lanka Association for the Advancement of Science, Sri Lanka, 110p.

Sandika AL, Seethagama SP and Jayamanne VS 2014 Knowledge and adoption of maintaining quality standards: A confectioneries producers' perspective. European Scientific Journal, .2:351 357.

Selvaraj A and Thuruchelvam S 2007 Factors affecting pesticides use by farmers in Vavuniya. Tropical Agricultural Research, 19:380-388.

Sumith J 2009 Daily News Online Edition/ archives.dailynews.lk/2001/pix/ Editorial. Oct 8, 2009 - Laws to tighten pesticide use.

Sumith JA and Muniittrick KR, 2011 Study design consideration for assessing the health of fish populations impacted by agriculture in developing countries. A Sri Lankan case study. Journal of Environmental Monitoring,113: 20693236.

Word Health Organization 1990 Safe use of pesticides. Fourteenth report of the WHO Expert Committee on Vector Biology and Control. Geneva, World Health Organization, WHO Technical Report Series, No.813. https:// apps.who.int/iris/handle/10665/41096. 